\title{
Pesquisa de células malignas circulantes em pacientes com melanoma maliǵno de coróide
}

\author{
Detection of circulating malignant cells in patients with uveal melanoma
}

\author{
Bruno F. Fernandes ${ }^{1}$ \\ Emilia Antecka ${ }^{2}$ \\ Gilberto dos Passos ${ }^{3}$ \\ Miguel N. Burnier Jr. ${ }^{4}$
}

\footnotetext{
Trabalho realizado no Hospital dos Servidores do Estado - Rio de Janeiro e McGill University - Montreal Canadá.

Oftalmologista do Departamento de Oftalmologia e Patologia da McGill University Health Center \& Henry C. Witelson Ocular Pathology Laboratory - Montreal - Canadá e Doutorando da Universidade Federal de São Paulo - UNIFESP - São Paulo (SP) - Brasil.

${ }^{2}$ Oftalmologista do Departamento de Oftalmologia e Patologia da McGill University Health Center \& Henry C. Witelson Ocular Pathology Laboratory - Montreal - Canadá

${ }^{3}$ Chefe do Departamento de Oftalmologia do Hospital dos Servidores do Estado - HSE - Rio de Janeiro (RJ) Brasil.

${ }^{4}$ Professor titular e Chefe do Departamento de Oftalmologia e Patologia da McGill University Health Center \& Henry C. Witelson Ocular Pathology Laboratory. Montreal - Canadá e Professor de Oftalmologia da UNIFESP - São Paulo (SP) - Brasil.

Endereço para correspondências: Bruno F. Fernandes. 3775 University Street, room 216 - Montreal - Quebec

- Canada H3A-2B4

E-mail: bruno.mtl@gmail.com

Recebido para publicação em 08.08.2006

Última versão recebida em 23.04.2007

Aprovação em 17.05.2007

Nota Editorial: Depois de concluída a análise do artigo sob sigilo editorial e com a anuência do Dr. Eduardo Ferrari Marback sobre a divulgação de seu nome como revisor, agradecemos sua participação neste processo.
}

\begin{tabular}{|l|}
\hline RESUMO \\
\hline Objetivo: Avaliar a possibilidade de identificação de células malignas \\
circulantes nas amostras de sangue periférico de pacientes brasileiros com \\
melanoma maligno de coróide enviadas para análise no exterior. Métodos: \\
Os marcadores melan-A e tirosinase foram usados para detectar a presença \\
de células malignas circulantes, pela transcrição reversa seguida de reação \\
em cadeia da polimerase e análise seqüencial de DNA (RT-nested-PCR), \\
em seis pacientes com melanoma maligno de coróide, diagnosticados no \\
Brasil. Resultados: Cinco pacientes deste grupo (83,33\%) foram conside- \\
rados positivos. A reação de RT-nested-PCR foi positiva para melan-A em \\
quatro (66,7\%) e positiva para tirosinase em quatro (66,7\%) dos seis \\
pacientes testados. Três (50\%) pacientes foram positivos para os dois \\
marcadores. Um (16,7\%) paciente foi negativo para ambos marcadores. \\
Conclusão: A pesquisa de células malignas circulantes usando RT- \\
nested-PCR, foi positiva na maioria dos pacientes estudados. A qualidade \\
das amostras de sangue periférico dos pacientes brasileiros foi mantida no \\
material preservado mesmo após ter sido enviado ao exterior.
\end{tabular}

Descritores: Melanoma; Neoplasias da coróide; Monofenol mono-oxigenase; Reação em cadeia da polimerase via transcriptase reversa; Análise de seqüência de DNA; Células neoplásicas circulantes

Objetivo: Avaliar a possibilidade de identificação de células malignas circulantes nas amostras de sangue periférico de pacientes brasileiros com melanoma maligno de coróide enviadas para análise no exterior. Métodos: Os marcadores melan-A e tirosinase foram usados para detectar a presença em cadeia da polimerase e análise seqüencial de DNA (RT-nested-PCR), em seis pacientes com melanoma maligno de coróide, diagnosticados no Brasil. Resultados: Cinco pacientes deste grupo $(83,33 \%)$ foram considequatro $(66,7 \%)$ e positiva para tirosinase em quatro $(66,7 \%)$ dos seis marcadores. Um $(16,7 \%)$ paciente foi negativo para ambos marcadores. Conclusão: A pesquisa de células malignas circulantes usando RTnested-PCR, foi positiva na maioria dos pacientes estudados. A qualidade das amostras de sangue periférico dos pacientes brasileiros foi mantida no \begin{abstract}
neplasicas circulantes
\end{abstract}

\begin{tabular}{l} 
INTRODUÇÃo \\
\hline O melanoma maligno uveal é o tumor maligno primário intra-ocular mais \\
comum na raça branca ${ }^{(1)}$ e representa $80 \%$ do total de casos de melanomas \\
não-cutâneos ${ }^{(2-3)}$. O melanoma maligno uveal apresenta uma incidência de \\
aproximadamente sete casos por milhão de pessoas por ano ${ }^{(1)}$. \\
A eficácia no diagnóstico e tratamento do melanoma maligno uveal \\
melhorou muito nos últimos anos. A oftalmoscopia, quando associada à \\
ultra-sonografia, apresenta precisão superior a $99 \%$ confirmada pelo diag- \\
nóstico anátomo-patológico ${ }^{(4-5)}$. A braquiterapia, ou radioterapia com pla- \\
cas suturadas à esclera, é a forma de radioterapia mais comumente usada no \\
tratamento dos melanomas malignos da coróide e do corpo ciliar, envol- \\
vendo a colocação de uma placa contendo uma fonte radioativa sobre a \\
esclera, na área do tumor ${ }^{(6)}$. \\
Apesar dos avanços no tratamento do tumor primário, a mortalidade \\
relacionada ao tumor não apresentou alteração significante. O melanoma \\
maligno de úvea apresenta altas taxas de metástase. Normalmente, as \\
metástases ocorrem muitos anos após o diagnóstico e tratamento do tumor \\
primário(7). Levantamentos estatísticos mais recentes estudaram as taxas de \\
sobrevida em cinco anos de pacientes com melanoma maligno uveal nos \\
Estados Unidos. Houve uma variação de $77 \%$ em 1973 para $84 \%$ em 1997 , \\
sem significância estatística ${ }^{(8)}$.
\end{tabular}


O fato de a úvea ser anatomicamente desprovida de vasos linfáticos faz com que o comportamento biológico do tumor seja diferente de outros sítios, impedindo a instauração de um sistema de estadiamento eficaz ${ }^{(9)}$. Assim, o desenvolvimento de um teste que defina a extensão da doença é um dos maiores desafios no manejo de pacientes com melanoma maligno de coróide.

A primeira tentativa de detecção de células malignas circulantes (CMCs) de tumores sólidos, usando transcrição reversa seguida de reação em cadeia da polimerase (RT-PCR) foi através ácido ribonucléico (RNA) da tirosinase em pacientes com melanoma maligno de pele ${ }^{(10)}$. Estudos posteriores realizados em pacientes com câncer de mama ${ }^{(11)}$, próstata $^{(12)} \mathrm{e}$ cólon $^{(13)}$, neuroblastoma ${ }^{(14)}$, hepatocarcinoma ${ }^{(15)}$ e melanoma de pele ${ }^{(16)}$ conseguiram detectar CMCs através de RT-PCR. Mais ainda, os resultados mostraram associação com estadiamento clínico e prognóstico ${ }^{(17)}$. A técnica de RT-PCR se tornou o método preferido por causa de sua alta sensibilidade, capaz de detectar até uma única célula por mililitro $(\mathrm{ml})$ de sangue periférico ${ }^{(18)}$.

Tobal et al. iniciaram os estudos a respeito da pesquisa de CMCs no melanoma maligno uveal, usando RT-PCR e apenas a tirosinase como marcador ${ }^{(19)}$. No entanto, estudos posteriores, envolvendo uma amostra maior de pacientes, falharam em detectar CMCs em casos de melanoma maligno uveal ${ }^{(18)}$. A importância da detecção de CMCs no melanoma maligno uveal ainda permanece nebulosa. Enquanto alguns autores encontraram correlação com pior prognóstico ${ }^{(20)}$ e presença de metástases $^{(21)}$, tal associação não foi demonstrada por outros ${ }^{(2)}$. Não foi encontrada nenhuma referência na literatura nacional quanto à pesquisa de $\mathrm{CMCs}$ em pacientes com melanoma maligno de coróide.

O objetivo do nosso estudo foi avaliar a possibilidade de identificação de células malignas circulantes no sangue periférico transportado à distância de pacientes com melanoma maligno de coróide diagnosticados no Brasil.

\section{MÉTODOS}

\section{Pacientes}

Seis pacientes do Hospital dos Servidores do Estado (Rio de Janeiro, Brasil), com melanoma de coróide foram incluídos no estudo. Os prontuários destes pacientes foram revisados com objetivo de coletar as seguintes informações: data do diagnóstico, data da radioterapia e/ou enucleação (quando aplicáveis), idade ao diagnóstico, sexo, maior dimensão tumoral, desenvolvimento de metástases, incluindo sítio afetado e data de detecção; e data da última consulta, incluindo condição clínica do paciente.

O tempo de seguimento, medido em meses, para os pacientes que não desenvolveram metástases foi definido como o intervalo entre a data do diagnóstico e a data da última consulta na qual foi averiguado o estado clínico do paciente. Já o tempo de seguimento para o grupo de pacientes que desen- volveram metástases foi definido como o intervalo entre a data do diagnóstico e a data da detecção da metástase.

\section{Coleta do sangue}

Foram coletados dez $\mathrm{ml}$ de sangue periférico de cada paciente, em tubos contendo ácido etilenodiamino tetra-acético (EDTA), através de punção venosa. Cada amostra foi processada de modo a separar a camada de células mononucleares, onde se encontram as $\mathrm{CMCs}^{(23)}$, usando-se o método Ficoll-Paque Plus (Amersham Biosciences), de acordo com as orientações do fabricante. O soro foi removido e o pellet foi resuspenso em solução de tiocinato de guanidina, e enviado para o Canadá em compartimento refrigerado por gelo seco. $\mathrm{O}$ envio do material foi feito seguindo-se toda regulamentação vigente no país.

\section{Extração de RNA}

Para a extração do RNA total a partir do pellet foi utilizada solução monofásica contendo fenol e tiocinato de guanidina (Trizol $^{\circledR}$, Invitrogen, Gaithersburg, MD, Estados Unidos), seguindo protocolo previamente descrito ${ }^{(24)}$. A quantidade e pureza do RNA total extraído são analisadas através da leitura em espectrofotômetro (Ultrospec 2000, Biochrom Ltda., Cambridge, UK).

\section{Síntese de ácido desoxirribonucléico complementar (cDNA)}

Dois microgramas $(\mu \mathrm{g})$ de RNA total de cada paciente foram incubados com solução que digere ácido desoxirribonucléico (DNA) de fita única ou dupla, na concentração de uma Unidade/

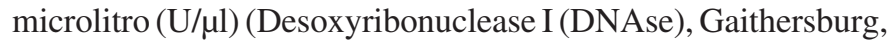
MD, Estados Unidos). Posteriormente, a DNAse é inativada pela adição de EDTA e calor. A mistura obtida (11 $\mu$ l) é então submetida imediatamente ao processo de transcrição reversa, adicionando-se $10 \mu \mathrm{l}$ de uma mistura contendo: $10 \mathrm{mM}$ de dNTP; $4 \mu \mathrm{l}$ de tampão $5 \mathrm{x}$ first strand; 0,1M de DTT (ditiotreitol, Invitrogen, Gaithersburg, MD, Estados Unidos); $40 \mathrm{U} / \mu \mathrm{l}$ de inibidor de RNAse (Amersham Biosciences); $200 \mathrm{U}$ de transcriptase reversa (Moloney murine leukemia virus, Invitrogen, Gaithersburg, MD, Estados Unidos).

Após a adição de todos os reagentes incuba-se a $37^{\circ} \mathrm{C}$ por 60 min e posteriormente inativa-se a reação aquecendo-a a $95^{\circ} \mathrm{C}$ por $10 \mathrm{~min}$. Terminada a reação de transcrição reversa, a mistura é diluída com água MilliQ autoclavada até o volume de $100 \mu \mathrm{l}$ e usada para a amplificação do DNA através da reação em cadeia de polimerase. O material não utilizado é mantido a $-20^{\circ} \mathrm{C}$. Uma amostra ausente de transcriptase reversa foi usada como controle negativo.

\section{Amplificação do DNA através da reação em cadeia de polimerase (PCR)}

Após a obtenção do cDNA, através da etapa de transcrição reversa, realiza-se a amplificação através de PCR do fragmento de cDNA correspondente ao mRNA da gliceraldeído-3fosfato-desidrogenase (GAPDH). Esta enzima é amplamente 
expressa em células sangüíneas, sendo útil para verificar a integridade do RNA extraído e a qualidade do cDNA sintetizado (controle interno). A expressão de $\beta$-actina foi avaliada com o mesmo propósito. Devido ao risco de resultado falso positivo decorrente de contaminação, realizou-se a reação de amplificação de uma amostra sem adição do cDNA (controle negativo).

A reação de amplificação é realizada utilizando-se $5 \mu \mathrm{l}$ de cDNA e 9,7 $\mu$ lde uma mistura contendo: $200 \mathrm{uM}$ de dNTP; $10 \mu \mathrm{M}$ de cada primer: Tirosinase (sense: 5' TTGGCAGATTGTCTGTAGCC e antisense: 5' AGGCATTGTGCATGCTGCTT) ou Melan-A (sense: 5' CACTCTTACACCACGGCTGA e antisense: 5' TAAGGTGGTGGTGACTGTTCTG) (Sheldon Biotechnology Centre, McGill University, Canadá); $50 \mathrm{mM} \mathrm{de} \mathrm{MgCl}_{2} ; 5 \mu \mathrm{l}$ de tampão 10x 1 U Taq polimerase (Invitrogen, Gaithersburg, MD, Estados Unidos).

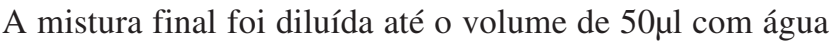
MilliQ autoclavada. A amplificação das sequiências de cDNA foi realizada no PTC-100 Thermal Controller (MJ Research Inc., Massachusetts, Estados Unidos) segundo o seguinte protocolo: Desnaturação inicial a $94^{\circ} \mathrm{C}$ por $4 \mathrm{~min} ; 30$ ciclos com temperatura de desnaturação de $94^{\circ} \mathrm{C}$ por 30 segundos, temperatura de anelamento de $54^{\circ} \mathrm{C}$ para melan-A ou $56^{\circ} \mathrm{C}$ para tirosinase por 45 segundos e temperatura de extensão de $72^{\circ} \mathrm{C}$ por 1 minuto (Figura 5); Extensão final a $72^{\circ} \mathrm{C}$ por 7 min. Cada reação foi realizada em triplicata para cada amostra de paciente.

\section{Amplificação seqüencial de DNA (Nested-PCR)}

Nested-PCR foi realizado a partir de $2 \mu \mathrm{l}$ do produto da reação anterior com a adição da mesma mistura utilizada na PCR. A única diferença na mistura foram os primers utilizados. Nessa fase, foram usados primers de nested-PCR que se ligam entre os primers primários usados anteriormente: Melan-A: sense (5' TCATCGGCTGTTGGTATTGTAG) e antisense (5', ATAAGCAGGTGGAGCATTGG); Tirosinase: sense (5' GTCTTTATGCAATGGAACGC) e antisense (5' GCTATCCCAGTAAGTGGACT) (Sheldon Biotechnology Centre, McGill University, Canadá).

Uma amostra onde o produto do PCR primário obtido foi excluído serviu como controle negativo para a etapa de nested-PCR. 25 ciclos adicionais foram realizados com temperatura de anelamento de $55^{\circ} \mathrm{C}$ para a melan-A e $56^{\circ} \mathrm{C}$ para a tirosinase. O produto final da amplificação da melan-A (245 bp) e da tirosinase (207 bp) foram visualizados em gel de agarose a 1,8\% contendo brometo de etídio (Invitrogen, Gaithersburg, MD, Estados Unidos). O paciente foi caracterizado como positivo quando ao menos um dos marcadores foi detectado. Todos os controles negativos para cada etapa do processo se mostraram negativos durante todo o experimento.

O protocolo deste estudo foi aprovado pelos comitês de ética da Universidade Federal de São Paulo e da Universidade McGill (McGill University Health Centre, Montreal, Canadá). O uso do material oriundo do Hospital dos Servidores do Estado (Rio de Janeiro, Brasil) foi autorizado pelo departamento de origem.

\section{RESULTADOS}

\section{Características do grupo estudado}

O grupo de pacientes pesquisados para a presença de CMCs foi composto de 6 pacientes. Os dados clínico-patológicos estão expostos na tabela 1. A idade ao diagnóstico foi de 58,8 $\pm 15,5$ anos (média \pm desvio padrão). Dois pacientes eram homens e quatro eram mulheres. A maior dimensão tumoral média foi de 10,6 $\pm 3,7 \mathrm{~mm}$ (média \pm desvio padrão). Em relação ao tratamento, dois haviam sido tratados com enucleação primária e dois foram submetidos à braquiterapia e enucleação após recidiva tumoral. Os dois pacientes restantes foram tratados conservadoramente, um deles com braquiterapia e termoterapia transpupilar (TTT), e o outro apenas com TTT com indocianina verde. Entre os pacientes que haviam sido enucleados, três apresentaram tumor de tipo celular misto e um do tipo fusiforme. A média de tempo entre o diagnóstico do melanoma maligno de coróide e a coleta do sangue foi de 34,8 \pm 15,0 meses (média \pm desvio padrão). A média de tempo entre o tratamento e a coleta do sangue foi de 19,7 \pm 19,2 meses (média \pm desvio padrão). A média de seguimento dos pacientes foi de $60 \pm 11,1$ meses (média \pm desvio padrão). Um paciente desenvolveu metástases hepáticas 11 meses após o diagnóstico, detectadas ao exame ultra-sonográfico.

\section{Resultados da pesquisa de CMCs}

Cinco pacientes deste grupo $(83,33 \%)$ foram considerados positivos. A reação de RT-nested-PCR foi positiva para melanA em quatro $(66,7 \%)$ (Figura 1) e positiva para tirosinase em quatro $(66,7 \%)$ (Figura 2) dos seis pacientes testados. Três $(50 \%)$ pacientes foram positivos para os dois marcadores. Um $(16,7 \%)$ paciente foi negativo para ambos marcadores. Os controles negativos foram todos negativos. A reação de RTPCR para GADPH e para $\beta$-actina foram ambas positivas para todos os pacientes, confirmando a qualidade do material contido nas amostras.

\section{DISCUSSÃO}

Os métodos diagnósticos atuais usados no seguimento de pacientes com melanoma maligno de coróide não são capazes de detectar precocemente a doença metastática. A sobrevida dos pacientes que desenvolvem metástases, principalmente hepáticas, é menor do que sete meses ${ }^{(25)}$.

Uma nova forma de se obter informação prognóstica em tumores sólidos é a pesquisa de disseminação hematogênica de células tumorais. Para tanto, a técnica de transcrição reversa seguida de reação em cadeia pela polimerase para o mRNA de marcadores histológicos é considerada como a mais indicada. No que se refere ao melanoma maligno de coróide, a literatura é escassa, com apenas seis artigos publicados em revistas indexadas, onde as taxas de detecção variam consideravelmente ${ }^{(18-22,26)}$. O marcador tumoral usado em tais trabalhos é a 


\begin{tabular}{|c|c|c|c|c|c|c|c|c|c|c|}
\hline Caso & Sexo & $\begin{array}{c}\text { Idade ao } \\
\text { diagnóstico } \\
\text { (anos) }\end{array}$ & $\begin{array}{l}\text { Maior } \\
\text { dimensão } \\
\text { tumoral } \\
(\mathrm{mm})\end{array}$ & $\begin{array}{c}\text { Tipo de } \\
\text { tratamento }\end{array}$ & $\begin{array}{l}\text { Tipo } \\
\text { celular }\end{array}$ & $\begin{array}{l}\text { Intervalo entre } \\
\text { diagnóstico } \\
\text { e coleta de } \\
\text { sangue (meses) }\end{array}$ & $\begin{array}{l}\text { Intervalo entre } \\
\text { tratamento } \\
\text { e coleta de } \\
\text { sangue (meses) }\end{array}$ & $\begin{array}{l}\text { Seguimento } \\
\text { (meses) }\end{array}$ & Metástase & CMCs \\
\hline 1 & $\mathrm{~F}$ & 52 & 11,7 & $\begin{array}{l}\text { radioterapia } \\
+ \text { enucleação }\end{array}$ & fusiforme & 36 & 10 & 48 & não & $\operatorname{sim}$ \\
\hline 2 & $\mathrm{~F}$ & 67 & 12,4 & $\begin{array}{l}\text { radioterapia } \\
+ \text { enucleação }\end{array}$ & misto & 28 & 4 & 67 & não & não \\
\hline 4 & $\mathrm{~F}$ & 42 & 10,0 & $\begin{array}{c}\text { radioterapia } \\
\quad+\text { TTT }\end{array}$ & $\mathrm{n} / \mathrm{a}$ & 38 & 30 & 68 & não & $\operatorname{sim}$ \\
\hline 5 & $\mathrm{~F}$ & 50 & 5,8 & $\begin{array}{l}\text { TTT com } \\
\text { indocianina }\end{array}$ & $\mathrm{n} / \mathrm{a}$ & 54 & 53 & 61 & não & sim \\
\hline 6 & $M$ & 76 & 14,0 & enucleação & misto & 19 & 18 & 44 & não & sim \\
\hline
\end{tabular}
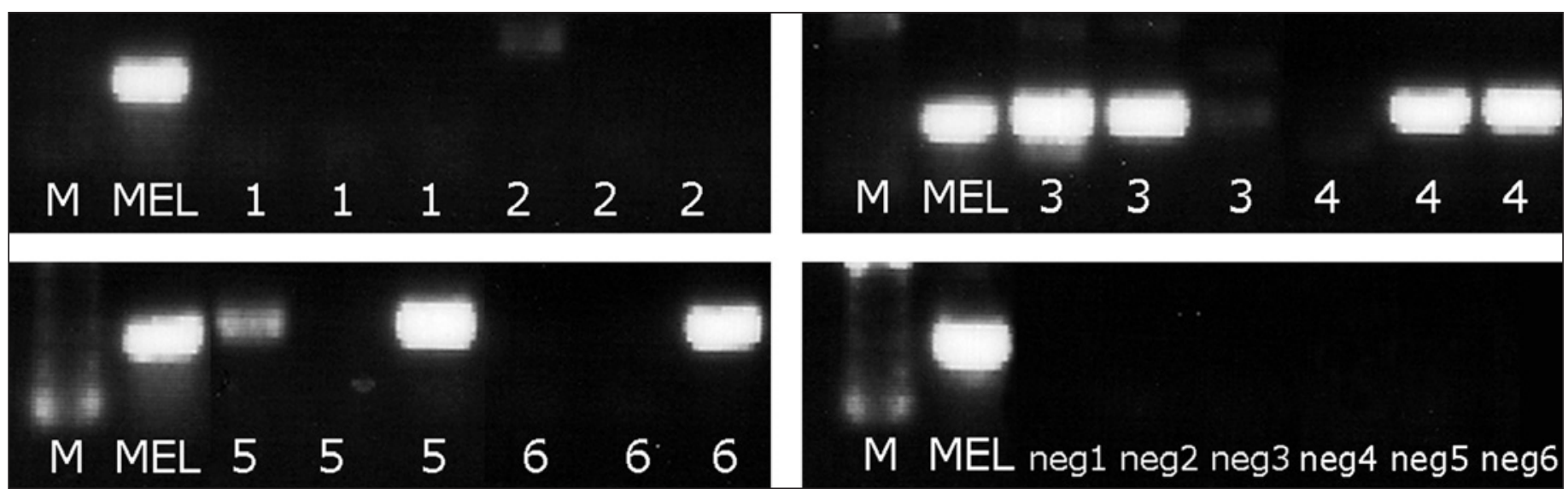

Figura 1 - Resultado do RT-nested-PCR para melan-A
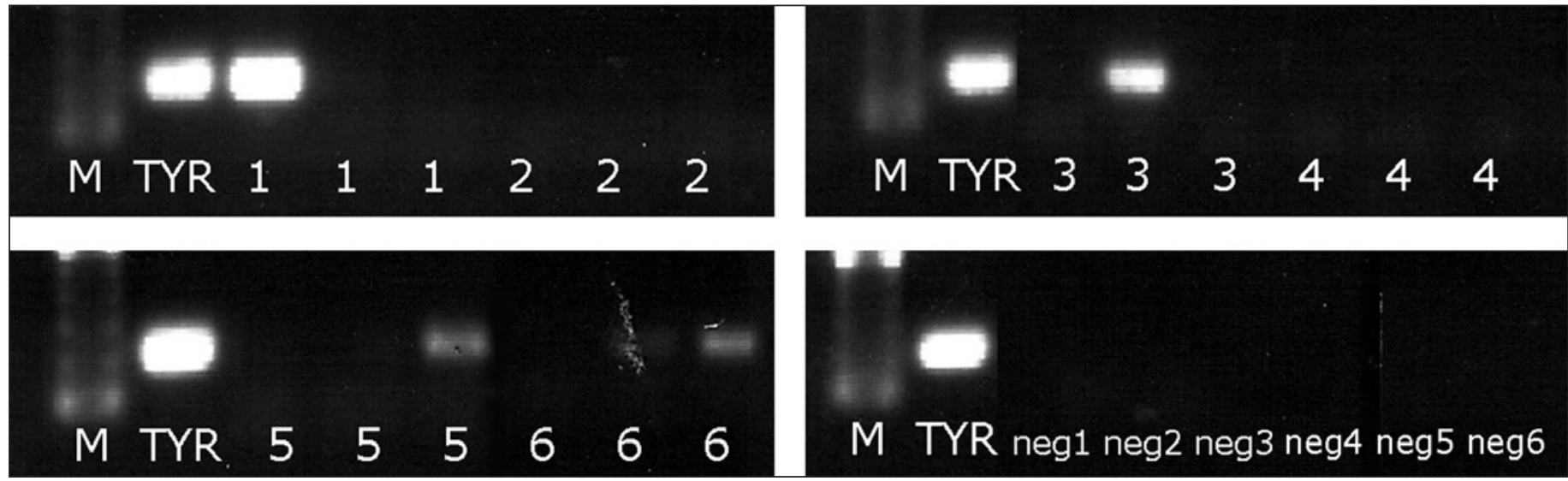

Figura 2 - Resultado do RT-Nested-PCR para tirosinase

tirosinase associada ou não à melan-A. A expressão de tais marcadores no tumor primário é alta, independente de qualquer característica clínico-patológica ou exposição à radioterapia ${ }^{(27)}$.

A primeira tentativa de pesquisa de CMCs usando RT-PCR para tirosinase no melanoma maligno de coróide foi feita por Tobal et al. ${ }^{(19)}$. Os resultados preliminares indicavam que a presença de CMCs era um importante indicador da ocorrência futura de metástases. Porém, o mesmo grupo publicou um outro trabalho alguns anos após onde 36 pacientes com melanoma maligno de coróide foram negativos para a presença de $\mathrm{CMCs}^{(18)}$. A relevância clínica da pesquisa de CMCs foi então questionada pelos autores.

Keilholz et al. estudaram um grupo de 21 pacientes com melanoma maligno de coróide sem metástases, porém apre- 
sentando fatores de risco para tanto (incluindo padrão de crescimento difuso, recorrência local, dimensão tumoral maior que $15 \mathrm{~mm}$, envolvimento do corpo ciliar e extensão extraocular), e outro grupo de 26 pacientes com melanoma maligno de coróide e doença metastática diagnosticada. A técnica utilizada foi a de RT-PCR em tempo real ("real time RT-PCR") para melan-A, tirosinase e gp100, onde é possível quantificar a presença de cada produto de transcrição. A melan-A e tirosinase foram detectadas em $4 \%$ e $12,5 \%$ dos pacientes do grupo sem metástases, respectivamente. No grupo com metástases, melan-A e tirosinase foram detectadas em $77 \%$ e $60 \%$ das amostras. Gp-100 não foi considerado um bom marcador por estar expresso também em indivíduos normais. Dois dos três pacientes positivos para CMCs, do grupo sem metástases, desenvolveram metástases ao longo do estudo. No mesmo grupo, entre os 17 pacientes que foram negativos para $\mathrm{CMCs}$, apenas 1 desenvolveu metástases ${ }^{(21)}$.

Um outro grupo de pesquisadores, inicialmente encontrou CMCs em dois de 12 pacientes com melanoma maligno de coróide usando RT-PCR para tirosinase ${ }^{(26)}$. Posteriormente, 41 pacientes com melanoma maligno de coróide foram testados e acompanhados por cinco anos para avaliar a relevância prognóstica do teste. No momento do diagnóstico, $39 \%$ dos pacientes foram positivos para CMCs, nenhum apresentava metástases. Uma semana após o tratamento, 69\% dos pacientes previamente positivos apresentaram resultados negativos. Apenas um paciente que havia sido negativo, apresentou resultado positivo após o tratamento. Durante o seguimento de cinco anos, a sobrevida se correlacionou com o resultado do RTPCR. Os pacientes com resultado positivo no momento do diagnóstico apresentaram um risco maior de morte ${ }^{(20)}$.

Recentemente, foi publicado um estudo prospectivo com 30 pacientes com melanoma maligno de coróide sem doença metastática. Vinte RT-nested-PCRs foram realizados para cada paciente, em cada visita trimestral. Vinte e nove dos 30 pacientes apresentaram resultado positivo em alguma visita. CMCs foram identificadas em pacientes recentemente diagnosticados, tratados com radioterapia, enucleação ou apenas observados, independente do tamanho tumoral, tipo de tratamento ou período de tempo decorrido após o tratamento. A discordância dos resultados deste último estudo com os anteriores pode ser explicada pela diferente metodologia: um maior volume de sangue, uso da técnica de análise seqüencial de DNA, maior número de RT-nested-PCRs por visita e a adição de um segundo marcador além da tirosinase, a melan-A, que se mostrou mais sensível ${ }^{(22)}$.

No trabalho apresentado, a dúvida maior era se o sangue coletado em pacientes no Brasil poderia ser transportado para um centro à distância, onde a pesquisa de CMCs pudesse ser feita sem sacrifício à qualidade do material. Foram coletados $10 \mathrm{ml}$ de sangue periférico de seis pacientes com melanoma maligno de coróide, nenhum deles com doença metastática identificada. O preparo e envio das amostras foi feito conforme descrito anteriormente ${ }^{(21)}$. A técnica de detecção foi similar à utilizada por Callejo et al. ${ }^{(22)}$. No grupo de pacientes testados, todas as amostras mantiveram a integridade do RNA nela contido. O cDNA formado teve sua qualidade testada e comprovada através da amplificação dos genes da $\beta$-actina e GAPDH. O método de coleta, transporte e detecção dos marcadores, utilizado neste estudo, se mostrou eficaz. Dos seis pacientes testados, cinco foram considerados positivos.

Apesar do pequeno número de pacientes, os resultados encontrados no nosso estudo estão de acordo com o trabalho de Callejo et al. ${ }^{(22)}$. As CMCs foram encontradas na maioria dos pacientes, independente do tamanho do tumor primário, tempo do diagnóstico ou tratamento. Mais ainda, tais achados corroboram a idéia de que a disseminação hematogênica ocorre precocemente, antes mesmo do diagnóstico ${ }^{(28)}$. Interessante notar que o teste foi positivo mesmo nos pacientes que foram enucleados e sem doença metastática detectada. É possível que as células circulantes sejam capazes de colonizar certos órgãos e permanecer em estado de latência por vários anos. Esses focos de micrometástases podem gerar a disseminação secundária de novas $\mathrm{CMCs}^{(29)}$.

A interpretação de um resultado negativo para presença de CMCs, deve ser feita com cautela. A presença de CMCs no sangue periférico não é um evento constante. No trabalho de Callejo et al. foram feitos um total de 2720 RT-nested-PCRs a partir de 1.360 amostras coletadas em 136 visitas. Apesar da maioria dos pacientes terem apresentado um resultado positivo, o número de testes positivos por visita foi pequeno ${ }^{(22)}$. Outra explicação para um resultado negativo é a perda da expressão dos marcadores de diferenciação melanocítica nas CMCs. As diferenças entre os perfis de expressão gênica do tumor primário e do foco metastástico foram estudados em um modelo animal de melanoma maligno de coróide ${ }^{(30)}$. O que se descobriu foi a presença de grupos de genes que tem sua expressão alterada durante a progressão para metástases. Enquanto a expressão de alguns genes é aumentada nas metástases, a de outros é diminuída. Neste segundo grupo de genes, estão os marcadores de diferenciação melanocítica.

Uma outra pergunta que surge é a importância prognóstica de se detectar CMCs no sangue periférico de pacientes com melanoma maligno de coróide. A simples presença de células tumorais na circulação não significa a ocorrência futura de metástases, já que grande parte destas células é destruída. Além disso, entre as células de uma neoplasia primária, mesmo entre aquelas que entram na circulação, a capacidade de originar metástases é diferente ${ }^{(31)}$. Mais ainda, a colonização de certo órgão por células malignas depende também de características locais do órgão-alvo e da interação intercelular ${ }^{(32)}$.

As descobertas recentes vêm mudando o foco do tratamento do melanoma maligno de coróide. Apesar do tratamento do tumor primário ter extrema importância, a influência na sobrevida do paciente é mínima. A doença sistêmica, presente ao momento do diagnóstico é a principal atenção das novas linhas de pesquisa. Somente o pleno entendimento da cascata de eventos que levam à formação e crescimento das metástases permitirá o desenvolvimento de terapias que melhorem o prognóstico do melanoma maligno de coróide. 


\section{CONCLUSÃO}

A pesquisa de células malignas circulantes usando RTnested-PCR, foi positiva na maioria dos pacientes estudados. A qualidade das amostras de sangue periférico dos pacientes brasileiros foi mantida no material preservado mesmo após ter sido enviado ao exterior.

\section{ABSTRACT}

Purpose: The purpose of our study was to detect circulating malignant cells (CMCs) in oversea-shipped blood samples of patients with uveal melanoma diagnosed in Brazil. Methods: Melan-A and tyrosinase were the two markers used for the detection of CMCs, using reverse transcriptase nested polymerase chain reaction (RT-nested-PCR) in 6 patients with uveal melanoma. The expression of $\beta$-actin and GAPDH were used to assess the quality of the material. Results: Five patients $(83.33 \%)$ tested positive for the presence of CMCs. The RT-nested-PCR was positive for melan-A in 4 patients $(66.7 \%)$ and positive for tyrosinase in $4(66.7 \%)$ of the 6 patients. Three $(50 \%)$ patients were positive for both markers. One $(16.7 \%)$ patient was negative for both markers. All negative controls were negative. Conclusion: The quality of the blood samples shipped overseas, from patients with uveal melanoma, was preserved. The detection of CMCs using RTnested-PCR was positive in the majority of the patients.

Keywords: Melanoma; Choroid neoplasms; Monophenol monooxygenase; Reverse transcriptase polymerase chain reaction; Sequence analysis, DNA; Neoplasm circulating cells

\section{REFERÊNCIAS}

1. Egan KM, Seddon JM, Glynn RJ, Gragoudas ES, Albert DM. Epidemiologic aspects of uveal melanoma. Surv Ophthalmol. 1988;32(4):239-51. Review.

2. Chang AE, Karnell LH, Menck HR. The National Cancer Data Base report on cutaneous and noncutaneous melanoma: a summary of 84,836 cases from the past decade. The American College of Surgeons Commission on Cancer and the American Cancer Society. Cancer. 1998;83(8):1664-78.

3. Albert DM, Dryja TP. The eye. In: Cotran RS, Kumar V, Collins T, Robbins SL, editors. Robbins pathologic basis of disease. $6^{\text {th }}$ ed. Philadelphia: W.B. Saunders; 1999. p.1359-77.

4. Accuracy of diagnosis of choroidal melanomas in the Collaborative Ocular Melanoma Study. COMS report nº. 1. Arch Ophthalmol. 1990;108(9):1268-73. Erratum in: Arch Ophthalmol. 1990;108(12):1708.

5. Histopathologic characteristics of uveal melanomas in eyes enucleated from the Collaborative Ocular Melanoma Study. COMS report nº. 6. Am J Ophthalmol. 1998;125(6):745-66. Comment in: Am J Ophthalmol. 1998;125(6):865-7.

6. Zhao DY, Shields CL, Shields JA, Gunduz K. Update on the management of posterior uveal melanoma. J Ophthalmic Nurs Technol. 1998;17(2):66-71.

7. Coupland SE, Sidiki S, Clark BJ, McClaren K, Kyle P, Lee WR. Metastatic choroidal melanoma to the contralateral orbit 40 years after enucleation. Arch Ophthalmol. 1996;114(6):751-6. Review.

8. Singh AD, Topham A. Survival rates with uveal melanoma in the United States: 1973-1997. Ophthalmology. 2003;110(5):962-5.

9. McLean IW. The biology of haematogenous metastasis in human uveal malignant melanoma. Virchows Arch A Pathol Anat Histopathol. 1993;422(6):433-7.

10. Smith B, Selby P, Southgate J, Pittman K, Bradley C, Blair GE. Detection of melanoma cells in peripheral blood by means of reverse transcriptase and polymerase chain reaction. Lancet. 1991;338(8777):1227-9.
11. Corradini P, Voena C, Astolfi M, Delloro S, Pilotti S, Arrigoni G, et al. Maspin and mammaglobin genes are specific markers for RT-PCR detection of minimal residual disease in patients with breast cancer. Ann Oncol. 2001;12(12):1693-8.

12. Zhang Y, Zippe CD, Van Lente F, Klein EA, Gupta MK. Combined nested reverse transcription-PCR assay for prostate-specific antigen and prostate-specific membrane antigen in detecting circulating prostatic cells. Clin Cancer Res. 1997;3(7):1215-20.

13. Jonas S, Windeatt S, O-Boateng A, Fordy C, Allen-Mersh TG. Identification of carcinoembryonic antigen-producing cells circulating in the blood of patients with colorectal carcinoma by reverse transcriptase polymerase chain reaction. Gut. 1996;39(5):717-21.

14. Naito H, Kuzumaki N, Uchino J, Kobayashi R, Shikano T, Ishikawa Y, Matsumoto S. Detection of tyrosine hydroxylase mRNA and minimal neuroblastoma cells by the reverse transcription-polymerase chain reaction. Eur $\mathrm{J}$ Cancer. 1991;27(6):762-5.

15. Matsumura M, Niwa Y, Hikiba Y, Okano K, Kato N, Shiina S, et al. Sensitive assay for detection of hepatocellular carcinoma associated gene transcription (alpha-fetoprotein mRNA) in blood. Biochem Biophys Res Commun. 1995;207(2):813-8.

16. Blaheta HJ, Paul T, Sotlar K, Maczey E, Schittek B, Paul A, et al. Detection of melanoma cells in sentinel lymph nodes, bone marrow and peripheral blood by a reverse transcription-polymerase chain reaction assay in patients with primary cutaneous melanoma: association with Breslow's tumour thickness. Br J Dermatol. 2001;145(2):195-202. Comment in: Br J Dermatol. 2001;145(2):193-4.

17. Battayani Z, Grob JJ, Xerri L, Noe C, Zarour H, Houvaeneghel G, et al. Polymerase chain reaction detection of circulating melanocytes as a prognostic marker in patients with melanoma. Arch Dermatol. 1995;131(4):443-7.

18. Foss AJ, Guille MJ, Occleston NL, Hykin PG, Hungerford JL, Lightman S. The detection of melanoma cells in peripheral blood by reverse transcriptionpolymerase chain reaction. Br J Cancer. 1995;72(1):155-9.

19. Tobal K, Sherman LS, Foss AJ, Lightman SL. Detection of melanocytes from uveal melanoma in peripheral blood using the polymerase chain reaction. Invest Ophthalmol Vis Sci. 1993;34(9):2622-5.

20. Boldin I, Langmann G, Richtig E, Schwantzer G, Ardjomand N, Wegscheider B, El-Shabrawi Y. Five-year results of prognostic value of tyrosinase in peripheral blood of uveal melanoma patients. Melanoma Res. 2005;15(6):503-7.

21. Keilholz U, Goldin-Lang P, Bechrakis NE, Max N, Letsch A, Schmittel A, et al. Quantitative detection of circulating tumor cells in cutaneous and ocular melanoma and quality assessment by real-time reverse transcriptase-polymerase chain reaction. Clin Cancer Res. 2004;10(5):1605-12.

22. Callejo SA, Antecka E, Blanco PL, Edelstein C, Burnier MN. Identification of circulating malignant cells and its correlation with prognostic factors and treatment in uveal melanoma. A prospective longitudinal study. Eye. 2007;21 (6):752-9. Epub 2006 Mar 31.

23. Callejo SA, Antecka E, Marshall JA, Connolly R, Burnier Jr MN. Detection of Spiked Uveal Melanoma Cells in Peripheral Blood of Healthy Volunteers. Invest Ophthalmol Vis Sci. 2003;44:E-Abstract 1550.

24. Chomczynski P, Sacchi N. Single-step method of RNA isolation by acid guanidinium thiocyanate-phenol-chloroform extraction. Anal Biochem. 1987; 162(1):156-9.

25. Shields JA, Shields CL, Donoso LA. Management of posterior uveal melanoma. Surv Ophthalmol. 1991;36(3):161-95.

26. El-Shabrawi Y, Langmann G, Hutter H, Kenner L, Hoefler G. Comparison of current methods and PCR for the diagnosis of metastatic disease in uveal malignant melanoma. Ophthalmologica. 1998;212(1):80.

27. Fernandes BF, Odashiro AN, Saraiva VS, Al-Kandari A, Bakalian S, Burnier Jr MN. Immunohistochemical Expression of Melanocytic Markers in Irradiated Uveal Melanoma. Invest Ophthalmol Vis Sci. 2006;47:E-Abstract 2237.

28. Eskelin S, Pyrhönen S, Summanen P, Hahka-Kemppinen M, Kivelä T. Tumor doubling times in metastatic malignant melanoma of the uvea: tumor progression before and after treatment. Ophthalmology. 2000;107(8):1443-9. Comment in: Ophthalmology. 2000;107(8):1441-2. Ophthalmology. 2001;108(5):829-31.

29. Demicheli R, Terenziani M, Valagussa P, Moliterni A, Zambetti M, Bonadonna G. Local recurrences following mastectomy: support for the concept of tumor dormancy. J Natl Cancer Inst. 1994;86(1):45-8.

30. Marshall JA, Nantel A, Blanco PL, Ash J, Cruess SR, Achenson E, Burnier Jr MN. Transcriptional Profiling of the Evolution of Uveal Melanoma From Cell Lines to Intraocular Tumors to Metastasis. Invest Ophthalmol Vis Sci. 2005;46:E-Abstract 3390

31. Fidler IJ, Kripke ML. Metastasis results from preexisting variant cells within a malignant tumor. Science. 1977;197(4306):893-5.

32. Fidler IJ. The pathogenesis of cancer metastasis: the 'seed and soil' hypothesis revisited. Nat Rev Cancer. 2003;3(6):453-8. 